\title{
Research on Channel Model and Price Dispersion of E-Commerce Market Based on Blockchain Technology
}

\author{
Qifeng Zhang ${ }^{1}$ and Fei Liu ${ }^{1,2}$ \\ ${ }^{1}$ The Graduate School, Woosuk University, Wanju, Republic of Korea \\ ${ }^{2}$ School of Economics, Hebei GEO University, Shijiazhuang 050030, China \\ Correspondence should be addressed to Fei Liu; liufei54adela@hgu.edu.cn
}

Received 10 September 2020; Revised 10 November 2020; Accepted 7 December 2020; Published 19 December 2020

Academic Editor: Hongju Cheng

Copyright (c) 2020 Qifeng Zhang and Fei Liu. This is an open access article distributed under the Creative Commons Attribution License, which permits unrestricted use, distribution, and reproduction in any medium, provided the original work is properly cited.

\begin{abstract}
In order to accurately predict the channels and prices of the e-commerce market, and thereby control the cost of the e-commerce market, this paper studies the channel model and price dispersion of the e-commerce market from the perspective of suppliers. First, this paper establishes a model to analyze the price dispersion structure under different proportions of informed consumers and theoretically analyzes the objective reasons for continued price dispersion in the e-commerce market where search costs have fallen sharply. Then, this article combines theoretical models with empirical research to study the price and price differences between the two types of retailers. The results show that as consumers' interest in retailers changes, prices will also change, and the degree of price dispersion in the e-commerce market has not yet converged. This research result has a good predictive effect on the pricing and market estimation of the e-commerce market and can control the cost of e-commerce operation and improve the competitiveness of the e-commerce market.
\end{abstract}

\section{Introduction}

The chain business is to instantaneously distribute through smart contracts, omitting the intermediate retention and transfer links, and there is no Party B and Party C, all of which are Party A, realizing direct value distribution. In the early stage of the Internet economy, based on the grasp of the characteristics of network information technology, scholars have generally believed that the application of ecommerce will have the following impact on both the supply and demand sides of the market. On the one hand, the scope of consumer search has been significantly expanded, and the search cost has been significantly reduced, which will promote the rationalization of consumer behavior $[1,2]$. On the other hand, retailers will face a wider range of interindustry competition. Although direct price competition can be partially avoided by means of bundling sales, the aggravation of competition will still lead to a considerable decline in the pricing power of manufacturers and make prices more transparent, which is undoubtedly conducive to consumer purchases [3-5]. In short, the e-commerce market is more efficient than the traditional offline trading market. This view is generalized as the "frictionless trading hypothesis" of the network economy and is widely accepted.

The reason why this paper studies the price dispersion in China's e-commerce market is mainly based on the following three considerations $[4,5]$ : (1) Price dispersion is an important index to test the efficiency of the market. Therefore, the study of price dispersion in the e-commerce market is the premise of investigating the efficiency of emerging markets and analyzing the behavior of manufacturers and consumers in the network economy [6]. It is of great significance to understand the current economic situation and future development. (2) Because it is very difficult to obtain the selling price of the same commodity and different merchants in the traditional market at the same time, most of the previous research on price dispersion is limited to theoretical research, and there is little empirical analysis. (3) The existing relevant research and conclusions are made based on the markets of developed countries such as Europe and the United States and are expanded and tested in China's market during the economic transition period $[7,8]$. 
Compared with the traditional market, it is easier for us to obtain cross-sectional price data of homogeneous goods, observable characteristic data of enterprises, and market characteristic data of products from the website [9-12]. Based on the above background, this paper analyzes the price level and price dispersion in the e-commerce market from the empirical point of view and analyzes the factors that affect the price level and price dispersion. This study has important theoretical significance for testing the efficiency of the network economy market and investigating its operation mechanism, and it also has extensive application value for the management and market competition of e-commerce enterprises.

The rest of this paper is organized as follows. Section 2 discusses the development foundation of China's agriculture, followed by agricultural industry chain reconstruction analysis and suggestions designed in Section 3. Relationship model and empirical research on network consumer behavior and e-commerce service quality is discussed in Section 4. Section 5 concludes the paper with a summary and future research directions.

\section{The Development Trend of E-Commerce}

2.1. The Development of E-Commerce Industry. In view of the unreasonable industrial structure and the inconsistency between supply and demand in macroeconomy, General Secretary Xi Jinping proposed to push forward the "supplyside structural reform" in macroeconomy in 2015. The policy objective of supply-side structural reform is to start from the supply side of economic development, eliminate backward production capacity, reduce enterprise operating costs, reduce excess inventory, and reduce excessive financial leverage. The shortcomings of enterprise operation quality and efficiency are completed, and a new mode of production with "innovation, coordination, green, open, and sharing" as the basic concept was established, to achieve the sustainable stability of the national economy and the transformation and upgrading of the development model [13-16].

The new concept of "supply-side structural reform" put forward by the state is to start with the supply-side factors of production to promote economic development, strengthen the top-level design, change the unreasonable industrial structure, and take the road of economic development of innovation, development, optimization, and upgrading. General Secretary Xi Jinping especially emphasized at the expert forum on economic situation held in July 2016 that the current national economic development has entered a new normal stage. Only by unswervingly pushing forward the structural reform on the supply side can we provide a new source of impetus for the healthy development of the national economy. Cross-border e-commerce is considered a strategic emerging industry under the new normal of China's economy and the macrobackground of supply-side structural reform.

Cross-border e-commerce refers to the various trading entities in different frontiers, each other through a crossborder e-commerce platform to achieve transaction matching, the use of cross-border logistics network to transport goods, through a variety of cross-border financial channels to complete payment and settlement of goods, and ultimately conclude the transaction. Compared with the traditional international trade, cross-border e-commerce, as an Internet-based operation mode, has the characteristics of strong transaction convenience, information transparency, and diversification. Cross-border e-commerce makes foreign trade activities no longer limited by material, time and space, and other factors, breaking through the time and space constraints of traditional foreign trade and gradually becoming a new way of international trade transactions. The supply-side structural reform puts forward that traditional industries should be transformed and upgraded and new and advantageous industries should be created through scientific and technological innovation $[17,18]$. The combination of China's traditional industries and cross-border e-business can create a new operation mode of "Internet plus traditional industries" and realize the integration of the real economy and the network economy. The advantages of science and technology were utilized to break through the gap between consumption demand and production supply, get rid of the dependence on traditional sales channels, and establish a brand new production and manufacturing response model to balance supply and demand [19]. The e-business supply chain model can be represented in Figure 1. At the same time, cross-border e-commerce breaks through the space-time constraints faced by traditional international trade by virtue of scientific and technological advantages, promotes global economic integration, and brings new impacts to the world economic and trade pattern [20]. Cross-border e-commerce can build a more open and diversified international economic and trade cooperation environment, which is conducive to China's foreign export enterprises to avoid trade barriers, expand export channels, and achieve optimal allocation of resources in various countries, which is of great importance to the realization of the national "one belt and one way" strategy [21]. China's cross-border e-commerce export industry, as a product of the close combination of traditional industry and Internet economy, can effectively solve the problem of mismatch between supply and demand in the foreign trade industry. The use of technological innovation for global consumers and suppliers of high-quality goods in China to build an effective trading platform to help China's traditional industries effectively releases capacity worldwide and removes inventory. The development of cross-border e-commerce conforms to the strategic plan of national supply-side reform and can provide a new grasp and impetus for deepening the supply-side reform in the field of foreign trade [22].

2.2. The Development of Cross-Border E-Commerce. The policy objective of the supply-side structural reform is to eliminate backward production capacity, reduce operating costs, reduce excess inventory, reduce excessive leverage of financial liabilities, and make up for the shortcomings of enterprise operating quality and efficiency. Due to the change of the international economic environment and the shrinkage of market demand, China's traditional foreign trade export industry is facing the situation of excess production 


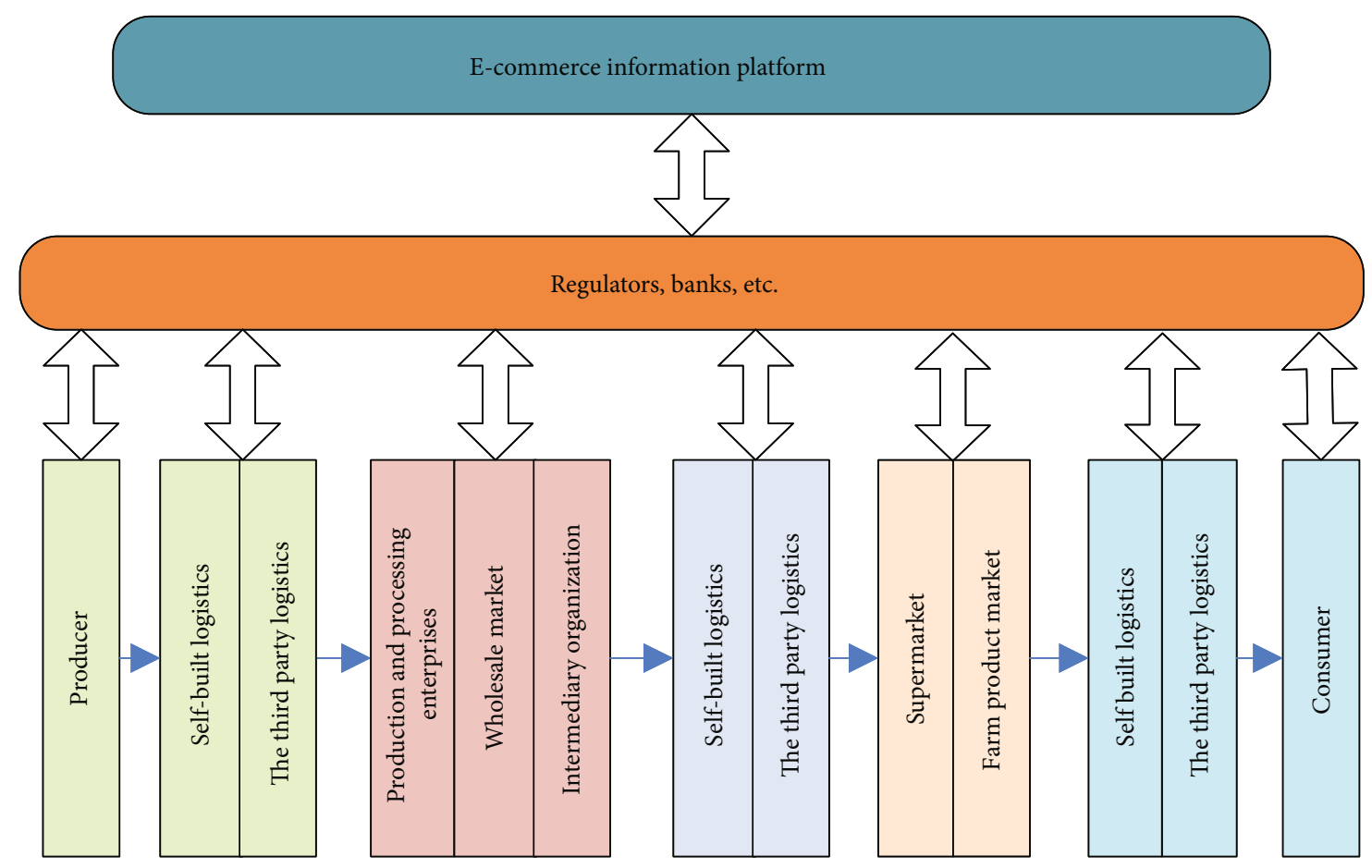

FIGURE 1: Commodity e-commerce supply chain schematic diagram.

capacity, product backlog, and difficult operation of enterprises. To deepen the supply-side reform in the field of foreign trade, the cross-border e-commerce industry provides a good solution path and examples [23].

In recent years, China's cross-border e-commerce industry has sprung up; benefiting from scientific and technological innovation and policy support, cross-border e-commerce can break through the constraints of the relatively weak international economic environment, develop rapidly, and become a highlight and hot spot of China's foreign trade development. In the process of supply-side structural reform, cross-border e-commerce can balance the contradiction between supply and demand worldwide through a market mechanism, digest excess capacity, and optimize product structure. With the advantages of Internet information technology, the foreign trade industry can realize the timely transmission of product supply and demand information through the cross-border e-commerce platform. Through the monitoring and analysis of the large-scale trading data, the foreign trade industry can timely screen and optimize the allocation of resources, find out the elimination of backward products, sort out the changing trend of product supply and demand structure, and provide a decision-making basis for the government to reduce production capacity, optimize the industrial layout, and implement all-round structural adjustment and transformation and upgrading [24]. Crossborder e-commerce provides more opportunities for smalland medium-sized enterprises to open up international markets and provide consumers with more personalized products and services [25]. The operation mode conforms to the changing trend of global consumption habits, breaks through the restrictions of time and geographical location, realizes the accurate matching of supply and demand in the global scope, releases the potential purchasing power, and improves the utilization rate of resources, thus promoting the growth of foreign trade volume and effectively eliminating the surplus stock in the foreign trade industry [26]. For example, in the "flash purchase" mode in cross-border e-commerce, enterprises with the advantages of scientific and technological information accurately grasp consumer psychology and behavior, in a specific time to focus on discount promotional activities for specified brand goods, in a short period of time to complete the cleaning of massive inventory. From the "deleveraging" point of view, cross-border e-commerce leverages the technological advantages of the Internet, opening up the cross-border demand and trade chain made in China, through high-frequency small fragmentation of the order operation mode to enhance trade volume, thereby alleviating the financial pressure of enterprises and reducing the tendency of enterprises to use excessive leverage. From the point of view of "cost reduction," cross-border e-commerce optimizes the supply and demand links between enterprises and consumers; reduces the information screening costs, transaction costs, and procurement costs of market participants; helps enterprises to improve operational efficiency; and opens up international markets at a lower cost. From the perspective of "complement board," cross-border ecommerce can use digital information technology to eliminate the widespread information mismatch, space-time mismatch, capacity mismatch, and other situations in foreign trade enterprises and promote high-quality production capacity "go out" by means of the Internet to promote China's foreign trade enterprises to expand the supply of high-end products, in order to increase the added value of 


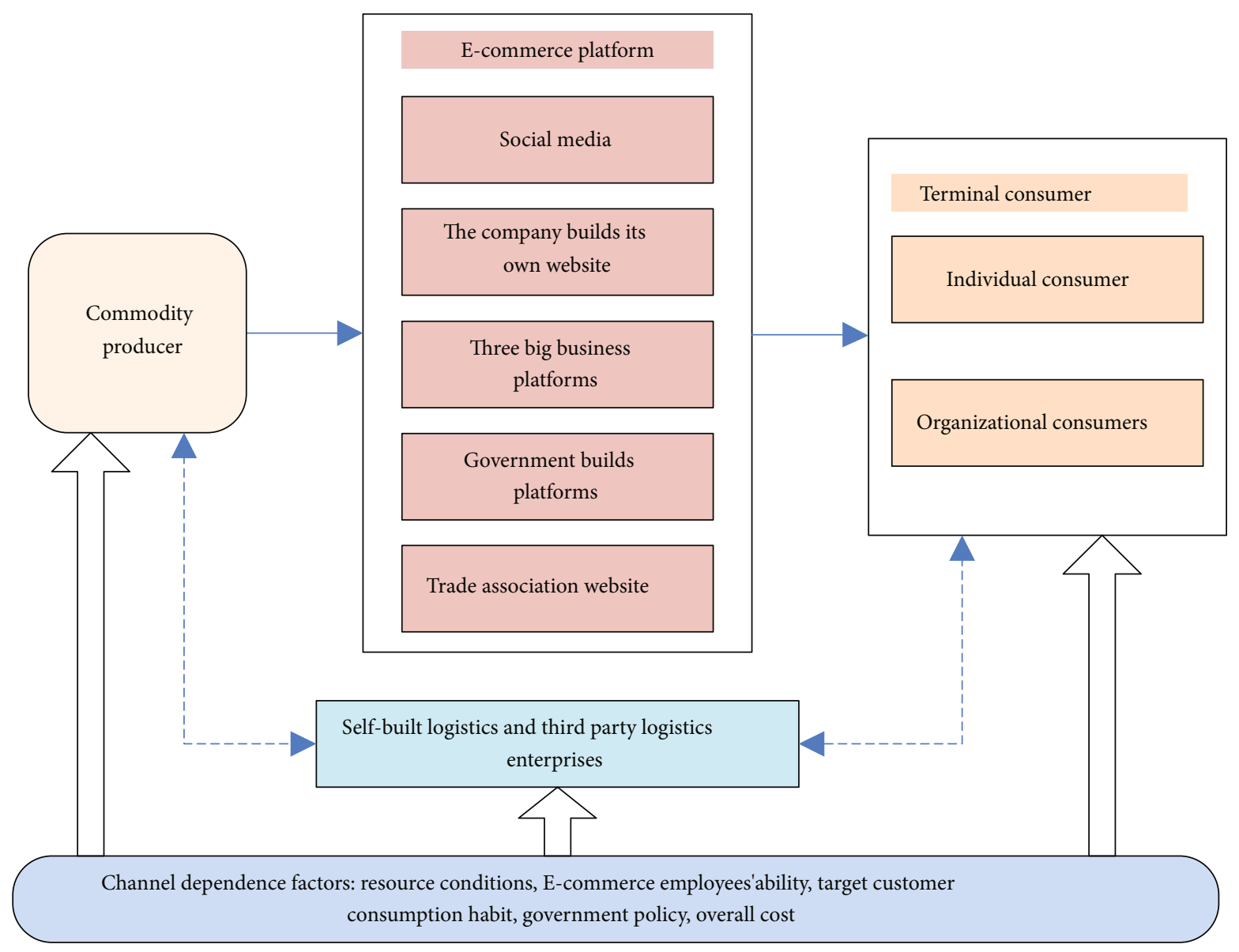

FIGURE 2: Channel pattern chart.

products, to make up for the lack of high-end products made in China's short board for economic innovation and development to open a new channel [27].

\subsection{Cross-Border E-Commerce in the Context of Lateral} Reform. China traditionally relies on resources, environment, demographic dividends, and other factors to accumulate foreign trade development advantages, but the current supplyside structural reform more emphasizes improving the quality of foreign trade supply from the system and innovation. The reform on the supply side of foreign trade emphasizes that the government should optimize the system supply and guarantee. The government should optimize the supply of public goods and services, reduce the institutional transaction costs of enterprises, and provide a driving force for cross-border e-commerce exports. At present, the development of cross-border e-commerce export has entered the stage of innovation-driven [28]. Enterprise performance must rely on all kinds of innovation, especially scientific and technological innovation to promote and achieve foreign trade economic growth. Innovation drive can give full play to the endogenous growth advantage of foreign trade and break the predicament of foreign trade from the supply side. Enterprises use the Internet platform to optimize social resources to carry out cross-border e-commerce; can stimulate the market entrepreneurs to innovate, through an innovative management mode, product design, and marketing services to drive upstream and downstream industrial chain to improve quality; cultivate brand; and tap China's foreign trade supply potential to create new supply. It is noteworthy that in addition to improving the quality of supply, crossborder e-commerce has also promoted the development of cross-border logistics, overseas warehousing, online payment, network marketing, and other emerging industries, changing the operation structure of traditional industries and realizing the transformation and upgrading of foreign trade. Cross-border e-commerce can also serve the country's "one belt and one road" strategic initiatives and build a new focus on the supply-side reform and expand the supply-side reform path and channel. Product producers establish business links with end-users through e-commerce platforms, such as social media, e-commerce companies, and industry websites. With the support of modern logistics, they have greatly met the demand of both suppliers and buyers for "selling" and "buying." Focusing on the structural elements of producers, consumers, e-commerce platforms, and logistics enterprises in the product upstream channel, five channels for developing product upstream ecommerce are constructed; the channel pattern chart is shown in Figure 2. 


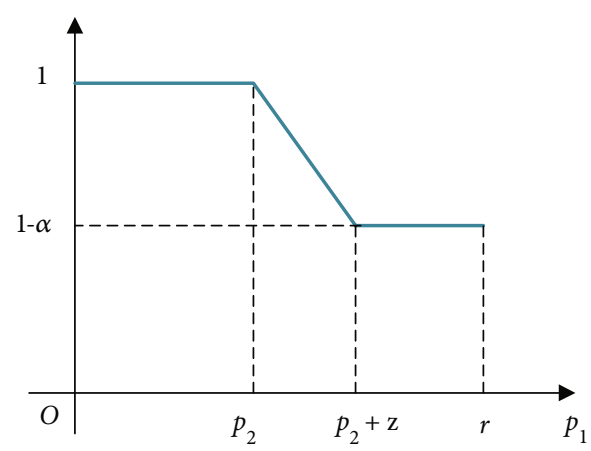

(a) Retailer 1 pricing

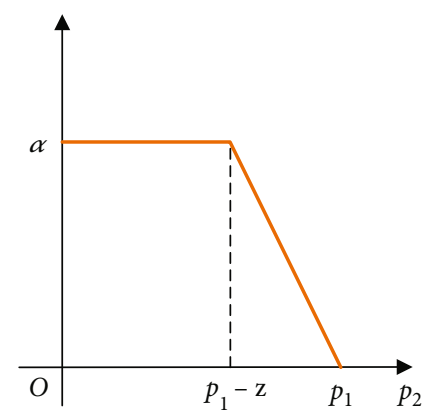

(b) Retailer 2 pricing

Figure 3: Pricing of retailers.

In an economic environment with obvious personal needs, cross-border e-commerce orders show a trend of high frequency and fragmentation. The scattered orders reflect the diversification and individualization of current consumer needs. The key to maintaining a competitive advantage in cross-border e-commerce lies in the integration of supply chain costs, flexible production arrangements, scientific inventory management, and ensured effective flow of funds, thereby reducing the financial risks faced by foreign trade companies through accurate supply. For demand matching, secondly, the use of social network platforms to carry out online marketing is a new trend for foreign trade companies to broaden the export channels of cross-border e-commerce, and cross-border e-commerce with the help of social platforms can play a gathering role. Third, the global promotion of mobile Internet and smartphones has promoted the intelligence and mobility of cross-border e-commerce operations. The mobile APP client of cross-border e-commerce can make it easy for consumers to shop, and it can also enable foreign trade companies to timely grasp supply and demand information and collect valuable data. Fourth, by improving the infrastructure of cross-border payment, overseas warehousing, and logistics, the cost of cross-border e-commerce can be controlled.

\section{Theoretical Analysis of Discrete Structure of Price}

Suppose there are two retailers selling the same commodity in a product market. One retailer has a high degree of consumer concern; the other has a low degree of consumer concern. Suppose that the unit marginal cost is $C$, and the reserve price is $R$, and $R>C$ in the market; suppose that the consumer buys a unit product at most.

Not only the difference of consumers themselves will lead to different search costs, but the difference of retailers will also lead to the difference in search costs. Assuming that the cost of searching unknown retailers is not less than that of searching famous retailers, the difference of search costs between retailers will lead to different degrees of concern of consumers. In order to reflect the different levels of concern that businesses receive, assume that all consumers are con- cerned about retailer 1; only some people can focus on retailer 2 through more patient search. Assuming that the number of retailers who can search for both types of retailers is $A, A$ reflects market transparency and the proportion of informed consumers.

In addition, the difference in search costs between retailers will lead to brand sensitivity (e.g., consumers may think that retailers without reputation are uncertain about the quality of the products they sell). Even if they sell homogeneous products, consumers are willing to pay a certain fee for famous retailers. Suppose that consumers have different brand preferences for retailers; that is, some consumers are reluctant to pay for the brand, while others are willing to buy from famous-brand retailers because they are more risk-averse or because of higher search costs. The same distribution from 0 to $Z$ reflects the sensitivity of consumers to retailers' brands.

In Figure 3(a), when the price of retailer 1 is lower than that of retailer 2, retailer 1 will win all consumers; when the price of retailer 1 is much higher than that of retailer 2 and the amount exceeds the maximum possible brand payment, retailer 1 will lose all consumers who know retailer 2. When the price of retailer 1 is higher than that of retailer 2, but it does not exceed the consumer's brand willingness to pay, retailer 1 can get all consumers who do not know retailer 2, and also those who have high brand payment. For retailer 2, as shown in Figure 3(b), if the set price is much lower than that of retailer 1 and the spread exceeds the consumer's maximum brand willingness to pay, retailer 2 can get all the consumers who know it. When the price of retailer 2 is lower than that of retailer 1 , but the price difference between retailer 2 and retailer 1 does not exceed the consumer's maximum brand willingness to pay, the market share decreases with the increase of the price until it loses all the market share at the same price as retailer 1 . The pricing of retailers is shown in Figure 3.

Assuming that retailers cannot distinguish consumers with different levels of concern and brand sensitivity and implement price discrimination strategy, refer to the Lal (1990) or Raju et al. (1990) demand model. The given price $\left(p_{1}, p_{2}\right)$ and exogenous variables $(a, z, r$, and $c)$, the demand $\left(q_{1}, q_{2}\right)$, and profit $\left(\pi_{1}, \pi_{2}\right)$ functions of two retailers are expressed as follows: 
$q_{1}= \begin{cases}1, & p_{1} \leq p_{2}, \\ 1-\alpha+\alpha \cdot \frac{p_{2}+z-p_{1}}{z}, & p_{2} \leq p_{1} \leq p_{2}+z, \\ 1-\alpha, & p_{2}+z \leq p_{1} \leq r,\end{cases}$

$\pi_{1}= \begin{cases}p_{1}-c, & p_{1} \leq p_{2}, \\ \left(1-\alpha+\alpha \cdot \frac{p_{2}+z-p_{1}}{z}\right) \cdot\left(p_{1}-c\right), & p_{2} \leq p_{1} \leq p_{2}+z, \\ (1-\alpha)\left(p_{1}-c\right), & p_{2}+z \leq p_{1} \leq r,\end{cases}$

$q_{2}= \begin{cases}\alpha, & p_{2} \leq p_{1}-z, \\ \alpha \cdot \frac{p_{1}-p_{2}}{z}, & p_{1}-z \leq p_{2} \leq p_{1}, \\ 0, & p_{1} \leq p_{2} \leq r\end{cases}$ $\pi_{2}= \begin{cases}\alpha\left(p_{2}-c\right), & p_{2} \leq p_{1}-z \\ \alpha \cdot \frac{p_{1}-p_{2}}{z} \cdot\left(p_{2}-c\right), & p_{1}-z \leq p_{2} \leq p_{1} \\ 0, & p_{1} \leq p_{2} \leq r\end{cases}$

According to the optimization problem and KuhnTucker sufficient and necessary conditions, it is known that retailer 1 and retailer 2 only exist pure strategy Nash equilibrium in three cases. For an interval in which there is no pure Nash equilibrium, there is at least one mixed strategy equilibrium. According to the necessary and sufficient conditions of mixed strategy equilibrium, two (continuous) distribution functions $\left(F_{1}\left(p_{1}\right), F_{2}\left(p_{2}\right)\right)$ are obtained to represent the equilibrium of a mixed strategy, such as the following formulas (2) and (3). These two distribution functions reflect the probability that the retailer's price is equal to or below a certain value:

$\left\{\begin{array}{l}F_{1}(r)=1, \\ \left(p_{2}-c\right) \alpha\left(1-F_{1}\left(P_{2}+z\right)\right)+\int_{p_{2}}^{p_{2}+z}\left(p_{2}-c\right) \alpha \frac{p_{1}-p_{2}}{z} f_{1}\left(p_{1}\right) d p_{1}=(p-z-c) \alpha, \quad \forall p_{2} \in[p-z, r-z], \\ F_{1}(p)=0,\end{array}\right.$

$$
\begin{aligned}
& \left\{\begin{array}{l}
F_{2}(r-Z)=1, \\
\left(p_{1}-c\right)(1-\alpha) F_{2}\left(P_{1}-z\right)+\int_{p_{1}-z}^{p_{1}}\left(p_{1}-c\right) \cdot\left[1-\alpha+\alpha \frac{p_{2}+z-p_{1}}{z}\right] \cdot f_{2}\left(p_{2}\right) d p_{2}+\left(p_{1}-c\right)\left(1-F_{2}\left(p_{1}\right)\right)=(r-c)(1-\alpha), \quad \forall p_{1} \in[p, r] \\
F_{2}(p-z)=0,
\end{array}\right. \\
& p_{1}=[p, r] \\
& p_{2}=[p-z, r-z], \\
& p=\max \left\{c+\frac{\sqrt{a z(r-c)(1-a)}}{a},(1-\alpha) r+a c\right\} .
\end{aligned}
$$

In which, $\left(F_{1}\left(p_{1}\right), F_{2}\left(p_{2}\right)\right)$ can be used to test a retailer's price behavior under various conditions by reflecting the complex price behavior characteristics, pure strategy, and Nash equilibrium of mixed strategy. It can be seen clearly that brand sensitivity affects the distribution of the price level. In order to study the variation of market price dispersion with the proportion of informed consumers, the equilibrium distribution function of mixed strategy formulas (2) and (3) are given $z=0$, at which time $p=\max \{c,(1-\alpha) r+\alpha c\}$ :

$$
\begin{cases}F_{1}\left(p_{1}\right)=1\left(f_{1}\left(p_{1}\right)=(1-\alpha)\right), & p_{1}=r \\ F_{1}\left(p_{1}\right)=1-\frac{(r-c)(1-\alpha)}{\left(p_{1}-c\right)}, & p_{1} \in[(1-\alpha) r+\alpha c, r] \\ F_{1}\left(p_{1}\right)=0, \quad p_{1} \in[0,(1-\alpha) r+\alpha c]\end{cases}
$$

$$
\left\{\begin{array}{l}
F_{2}\left(p_{2}\right)=1\left(f_{2}\left(p_{2}\right)=0\right), \quad p_{2}=r \\
F_{2}\left(p_{2}\right)=\frac{1}{\alpha}-\frac{(r-c)(1-\alpha)}{\left(p_{2}-c\right) \alpha}, \quad p_{2} \in[(1-\alpha) r+\alpha c, r] \\
F_{2}\left(p_{2}\right)=0, \quad p_{2} \in[0,(1-\alpha) r+\alpha c] .
\end{array}\right.
$$

The assumption that consumer brand sensitivity $z=0$ means that consumers in the market are reluctant to pay for the retailer's brand. This is an extreme scenario, but because the various search tools provided by the Internet can constantly provide product/service quality information for the retailers covered, it is possible to reduce the uncertainty of online consumers buying goods from nonbranded retailers. Under this assumption, we can independently 


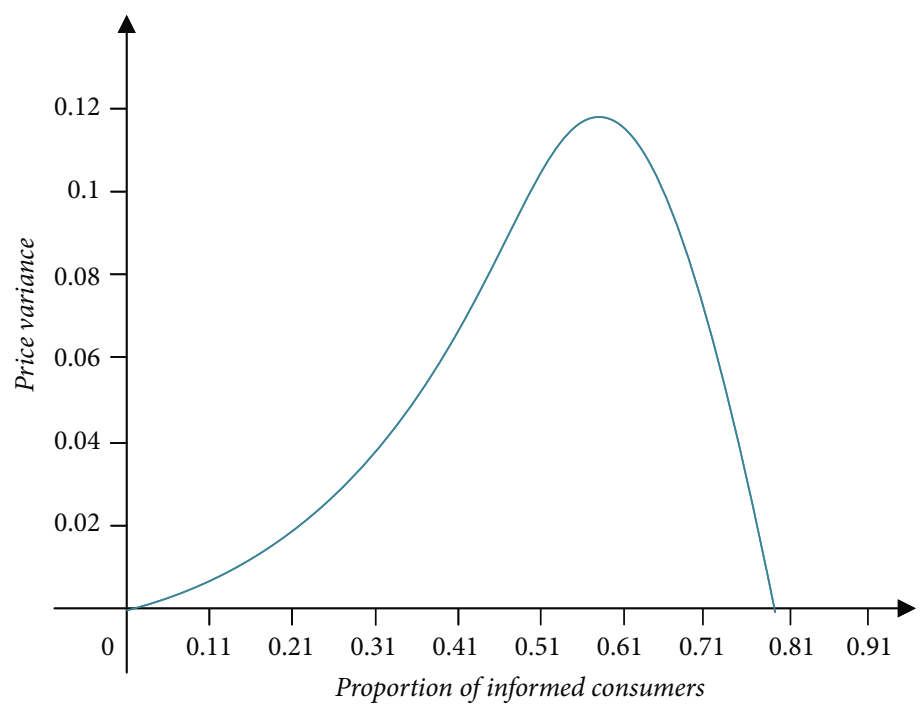

FIgURE 4: Convergence and expansion of price dispersion.

analyze the price dispersion of consumers under different attention $\alpha$. The variance of $p_{1}$ and $p_{2}$ difference is further calculated:

$$
\begin{aligned}
\operatorname{Var}\left(p_{1}-p_{2}\right)= & \operatorname{Var}\left(p_{1}\right)+\operatorname{Var}\left(p_{2}\right) \\
= & (r-c)^{2}(1-\alpha)[2 \alpha+2(1-\alpha) \ln (1-\alpha) \\
& \left.-(1-\alpha)\left[1+\frac{1}{a^{2}}\right] \ln ^{2}(1-\alpha)+1\right]
\end{aligned}
$$

The variance of the price difference set by the two retailers is a measure of the dispersion of the two retail prices. Looking at the right side as a function of $\alpha$, you can see that the size of $R$ and $C$ only changes the size of the function, not the shape of the function. Let us set up $c=0, r=1$, get the following Eq. (8). The convergence and expansion of price divergence are shown in Figure 4:

$$
\begin{aligned}
\operatorname{Var}\left(p_{1}-p_{2}\right)= & (1-\alpha)[2 \alpha+2(1-\alpha) \ln (1-\alpha) \\
& \left.-(1-\alpha)\left[1+\frac{1}{a^{2}}\right] \ln ^{2}(1-\alpha)+1\right] .
\end{aligned}
$$

It can be seen that the price dispersion will increase with the increase of consumer attention until the consumer attention reaches a very high value $(\alpha \approx 0.83)$; that is, when all consumers become informed consumers, the price dispersion reaches the maximum value, and then, the increase of consumer attention sharply reduces to the marginal cost. The conclusion seems counterintuitive, but it properly explains the objective phenomenon that the price dispersion of the e-commerce market does not converge or even expand, which is consistent with the international research results in recent years. With the popularization and use of information technology such as search engines, price dispersion still exists when the cost of information search is significantly reduced and more consumers become insiders:
TABLE 1: Range comparison table.

\begin{tabular}{lccc}
\hline Number of periods & MCRs & Dotcoms & All \\
\hline 1 & 198.55 & 219.67 & 409.96 \\
2 & 146.98 & 199.14 & 363.57 \\
3 & 149.69 & 182.78 & 347.86 \\
4 & 172.31 & 201.21 & 354.44 \\
5 & 159.778 & 131.88 & 320.73 \\
6 & 149.78 & 185.47 & 328.19 \\
7 & 145.449 & 154.96 & 317.47 \\
8 & 139.98 & 142.39 & 322.83 \\
9 & 145.37 & 152.39 & 299.88 \\
10 & 118.16 & 117.98 & 293.24 \\
11 & 121.55 & 117.42 & 390.65 \\
12 & 110.21 & 115.65 & 329.88 \\
13 & 112.21 & 106.38 & 298.32 \\
14 & 114.78 & 121.58 & 378.88 \\
15 & 133.98 & 141.93 & 362.26 \\
16 & 152.59 & 153.87 & 355.63 \\
Total mean value & 141.96 & 152.79 & 342.11 \\
\hline
\end{tabular}

$\alpha=1$ in formula (5) and (6) can be obtained:

$$
F_{1}(c)=F_{2}(c)=1
$$

That is, when the consumer brand is insensitive $(z=0)$, and the market information is sufficient, all consumers know all the retailers $(\alpha=1)$, then achieve complete competition in the Bertand model; the retailer must price at marginal cost $c$; otherwise, there is no consumer. On the other hand, consumer brand insensitivity $(z=0)$ and full market information $(\alpha=1)$ are necessary conditions for pure price competition. As long as consumers have brand loyalty, or not all consumers know all retailers, enterprises will make extra profits. 


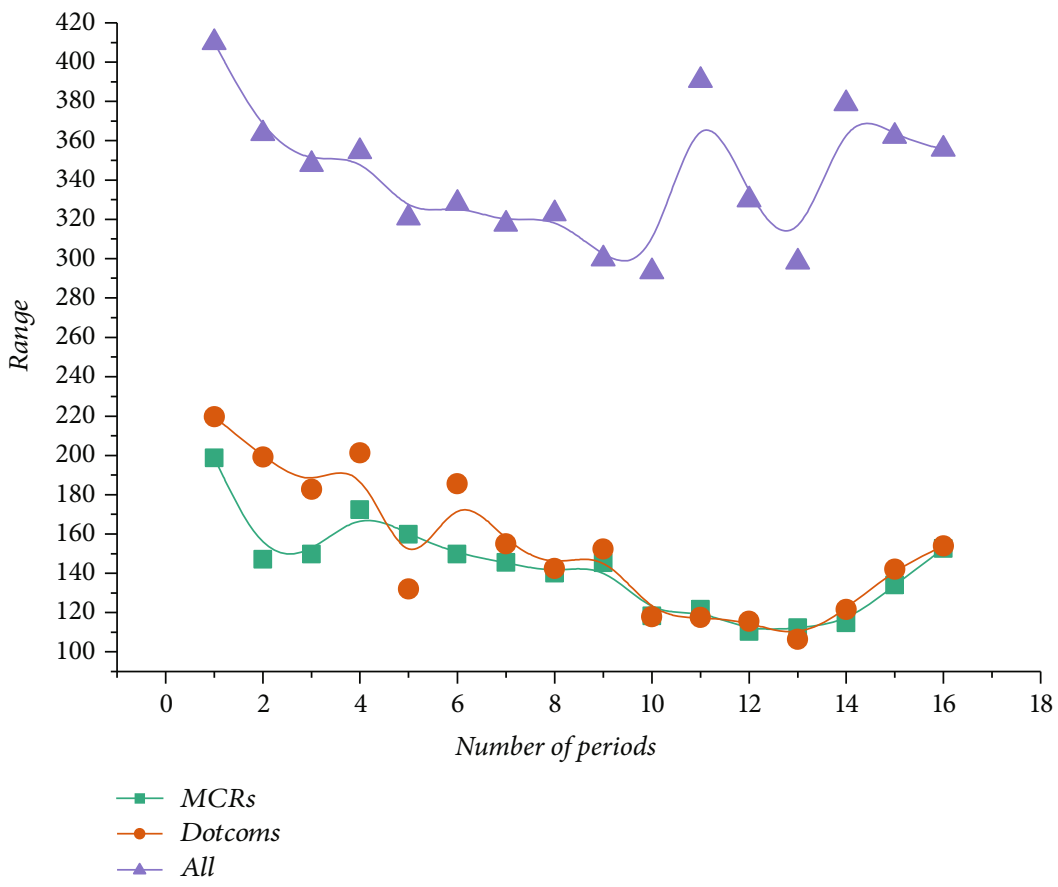

Figure 5: Extreme time trend chart.

In summary, price dispersion will persist if the two conditions $z=0$ and $\alpha=1$ hold for different levels of consumer concern or consumers are sensitive to the seller's brand.

\section{Empirical Analysis of Retailer Price Dispersion in E-Commerce Market}

Based on the grasp of the characteristics of network information technology, the "frictionless transaction hypothesis" of the network economy has been widely accepted by scholars. E-commerce will effectively reduce the market price and price deviation. In addition, more and more traditional offline retailers recognize the importance of online channels and begin to dabble in online sales, which can be called "multichannel retailers" (MCRs) or "pure online retailers" (Dotcoms). Therefore, this paper adopts the method of combining the theoretical model with empirical research to study the price and price dispersion between the above two types of retailers and compares whether the price and price deviation of the same product between different online retailers in the e-commerce environment are significantly reduced.

4.1. Statistical Analysis of the Extreme Price Difference of Commodities. The definition of the extreme difference is the difference between the maximum and minimum values of goods. In this paper, the price range is "the difference between the maximum and the minimum of the same commodity price of different retailers of the same type at the same time." The expression is as follows:

$$
R=\text { Maximum value }- \text { Minimum value }
$$

Based on the statistical analysis of the data, it is concluded that the difference between the two types of retailers' sales of
TABLE 2: Standard deviation comparison table.

\begin{tabular}{lccc}
\hline Number of periods & MCRs & Dotcoms & All \\
\hline 1 & 99.64 & 115.98 & 143.28 \\
2 & 89.88 & 105.83 & 117.65 \\
3 & 93.12 & 80.21 & 124.32 \\
4 & 87.87 & 95.38 & 115.98 \\
5 & 85.43 & 88.96 & 108.69 \\
6 & 84.24 & 87.72 & 98.25 \\
7 & 75.48 & 80.77 & 86.59 \\
8 & 68.54 & 75.57 & 97.28 \\
9 & 65.62 & 71.35 & 103.89 \\
10 & 64.62 & 71.21 & 89.31 \\
11 & 64.58 & 71.48 & 110.66 \\
12 & 60.64 & 66.68 & 136.82 \\
13 & 68.61 & 71.86 & 98.76 \\
14 & 69.22 & 76.21 & 99.43 \\
15 & 70.35 & 73.47 & 118.12 \\
16 & 70.83 & 81.87 & 134.12 \\
Total mean value & 76.17 & 82.16 & 111.45 \\
\hline
\end{tabular}

all mobile phone products varies with time as shown in Table 1.

According to the above table, the time trend chart for plotting range variation is shown in Figure 5.

The range comparison table and the extreme time trend table of the two types of retailers can be obtained; the average price range for Dotcoms retailers is 152.79, while the average price range for MCR retailers is 141.96. Dotcoms retailers have greater price fluctuations than MCR retailers. The price ranges of both retailers have shown a downward trend. The 


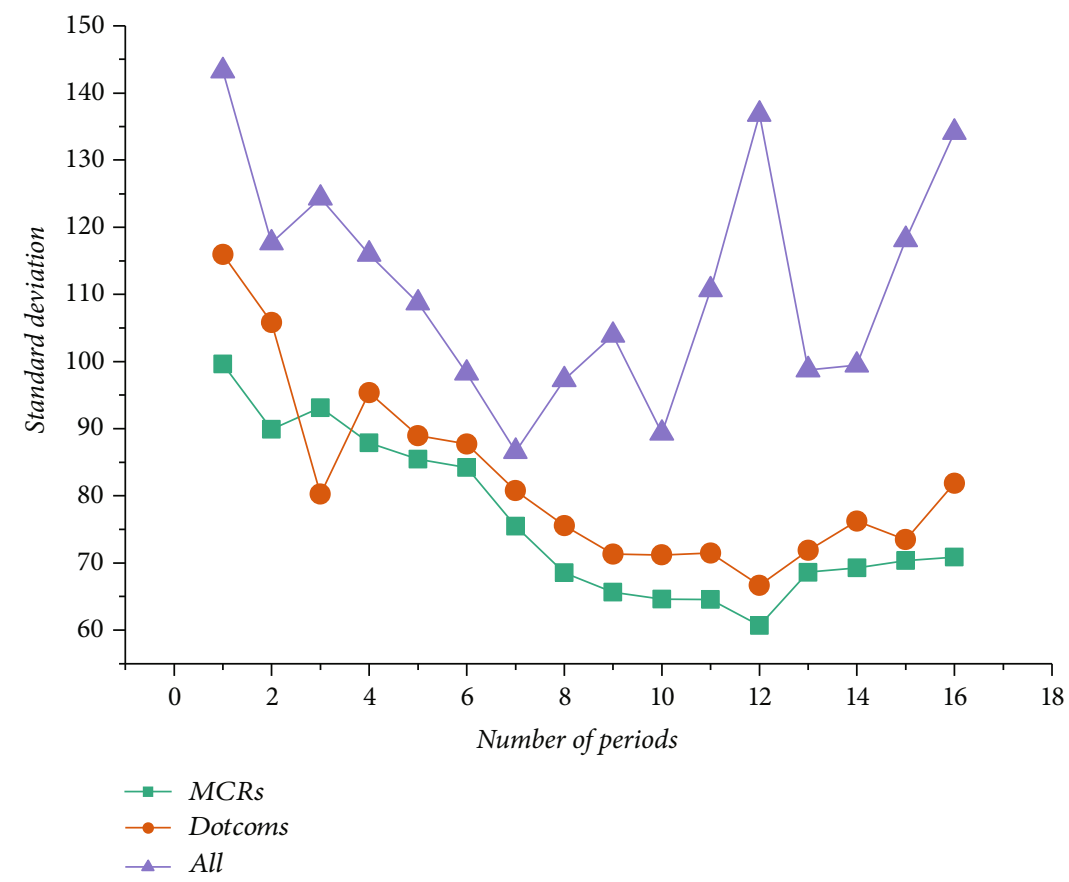

FIGURE 6: Price standard deviation time trend chart.

reason is that with the advent of the peak sales season, retailers have shown higher efficiency in their pricing strategies, so the price range between the two types of retailers tends to shrink.

4.2. Statistical Analysis of Commodity Price Standard Deviation. The price standard deviation is the square root of the ratio of the sum of squares of the difference between the price and the mean value of the price $(n-1)$ :

$$
\mathrm{SD}=\sqrt{\frac{1}{n-1} \sum_{i=1}^{n}\left(x_{i}-\bar{x}\right)^{2}}
$$

The trend of price deviation of all two types of retailers is shown in Table 2.

The trend chart of the change in price standard deviation is shown in Figure 6.

It can be seen from Table 2 and Figure 6, in addition to the third issue, that the price standard deviation of Dotcoms is higher than that of MCRs. The average price standard deviation of Dotcoms is 82.16, while that of MCRs is 76.17. This is consistent with the conclusion of extreme difference analysis. The price dispersion of Dotcoms is greater than that of MCRs.

In the early period, the price standard deviation between the two is obviously different, and in the sixth and seventh periods, the price standard deviation of the two is consistent; the difference is not significant, which also reflects the "holiday effect" of retailer pricing.

4.3. Statistical Analysis of Price Dispersion Rate. Generally speaking, the discrete rate is the ratio of the standard devia-
Table 3: Price dispersion rate comparison table.

\begin{tabular}{lccc}
\hline Number of periods & MCRs & Dotcoms & All \\
\hline 1 & 0.053 & 0.051 & 0.071 \\
2 & 0.049 & 0.056 & 0.061 \\
3 & 0.049 & 0.045 & 0.064 \\
4 & 0.048 & 0.052 & 0.051 \\
5 & 0.047 & 0.04 & 0.057 \\
6 & 0.047 & 0.049 & 0.053 \\
7 & 0.044 & 0.047 & 0.049 \\
8 & 0.041 & 0.045 & 0.054 \\
9 & 0.038 & 0.043 & 0.058 \\
10 & 0.038 & 0.043 & 0.051 \\
11 & 0.038 & 0.043 & 0.061 \\
12 & 0.039 & 0.041 & 0.073 \\
13 & 0.042 & 0.044 & 0.057 \\
14 & 0.043 & 0.046 & 0.057 \\
15 & 0.044 & 0.046 & 0.067 \\
16 & 0.045 & 0.051 & 0.077 \\
Total mean value & 0.043 & 0.046 & 0.06 \\
\hline
\end{tabular}

tion to the mean. Therefore, in this paper, the price discrete rate refers to the degree of deviation of the price distribution of the same commodity relative to a central price distribution in the market. This paper adopts the ratio of price standard deviation to average price to measure the price dispersion rate. That is,

$$
\mathrm{DR}=\frac{\mathrm{SD}}{\text { average }(\text { Price })}
$$




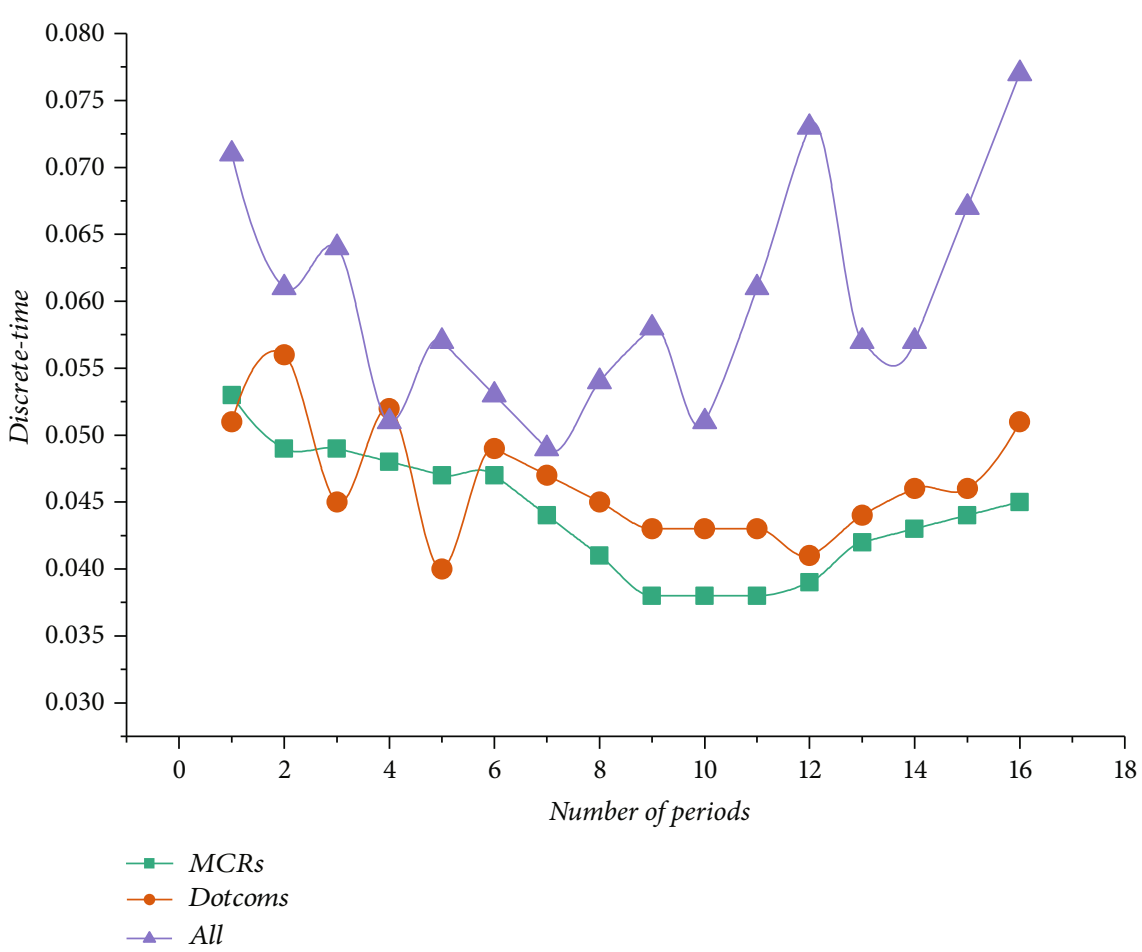

Figure 7: Price dispersion rate time trend chart.

The price dispersion rate of all two types of retailers varying with time is shown in Table 3.

The trend of the price dispersion rate is shown in Figure 7.

It can be seen from Table 3 and Figure 7 that the average price dispersion rate of Dotcoms retailers is 0.046 , and that of MCR retailers is 0.043 . Dotcoms retailers are higher than MCR retailers. The trend of the price dispersion rate of the two retailers is roughly the same as the trend of the price standard deviation. By comparing and analyzing the price range, standard deviation, and price dispersion rate of all mobile phone products sold by the two retailers, we can draw the following conclusions: Dotcoms retailer's extreme deviation, standard deviation, and dispersion rate average are higher than MCR retail. In most periods, the three trends of the two types of sellers are almost the same.

\section{Conclusion}

The results show that the price dispersion of the e-commerce market is not convergent, and the price dispersion is not a temporary phenomenon of the immature e-commerce market. It will be universal and persistent: as long as consumers are brand sensitive or not all consumers are concerned about all retailers, prices vary between retailers with different levels of attention. When using the price dispersion index to measure the market efficiency, it is necessary to determine the proportion of informed consumers in the market, because when the proportion of informed consumers is lower than a fairly high proportion, the price dispersion will actually increase with the proportion of informed consumers. Price dispersion is a common phenomenon in the products studied in this paper. The price dispersion of cosmetics, audiovisual products, gifts, and books is greater. The characteristics of retailers have a significant impact on prices. The study shows that there are three types of e-commerce retailers in China's e-commerce market which are aimed at different consumer groups, and their pricing bases are different. No matter what type of retailer, the provision of quality service does not necessarily mark a higher price. The net sellers who enter the online market earlier will have lower prices.

\section{Data Availability}

All data is true and reliable and can be obtained by contacting the corresponding author.

\section{Conflicts of Interest}

We declare that there is no conflict of interest regarding the publication of this paper.

\section{References}

[1] L. Wang, Q. Wu, J. Elliot, F. R. Fiedler, and S. Lapin, "Linear diffusion-wave channel routing using a discrete Hayami convolution method," Journal of Hydrology, vol. 509, no. 2, pp. 282-294, 2014.

[2] J. Sha, W. Wu, T. Lv, and W. Wu, "Coordination of advertising free riding in hybrid channel supply chain," Discrete Dynamics in Nature and Society, vol. 2016, Article ID 7423043, 9 pages, 2016.

[3] R. Wang, P. Wang, G. Xiao, and S. Gong, "Power demand and supply management in microgrids with uncertainties of 
renewable energies," International Journal of Electrical Power \& Energy Systems, vol. 63, no. 12, pp. 260-269, 2014.

[4] M. Gümüş, S. Li, W. Oh, and S. Ray, "Shipping fees or shipping free? A tale of two price partitioning strategies in online retailing," Production \& Operations Management, vol. 22, no. 4, pp. 758-776, 2013.

[5] A. J. Heitmann and R. S. Gardiner-Garden, "A robust feature extraction and parameterized fitting algorithm for bottom-side oblique and vertical incidence ionograms," Radio Science, vol. 54, no. 1, pp. 115-134, 2019.

[6] X. Nie, T. Boyac1, M. Gümüş, S. Ray, and D. Zhang, "Joint procurement and demand-side bidding strategies under price volatility," Annals of Operations Research, vol. 257, no. 1-2, pp. 121-165, 2017.

[7] X. K. Xie, R. Verma, and C. K. Anderson, "Demand growth in services: a discrete choice analysis of customer preferences and online selling," Decision Sciences, vol. 47, no. 3, pp. 1450-1462, 2016.

[8] L. Xia and B. Shihada, "A Jackson network model and threshold policy for joint optimization of energy and delay in multihop wireless networks," European Journal of Operational Research, vol. 242, no. 3, pp. 778-787, 2015.

[9] Q. Pang, Y. Chen, and Y. Hu, “Three-level supply chain coordination under disruptions based on revenue-sharing contract with price dependent demand," Discrete Dynamics in Nature and Society, vol. 2014, Article ID 464612, 11 pages, 2014.

[10] S. Hurkens and Á. L. López, "Mobile termination, network externalities and consumer expectations," Economic Journal, vol. 124, no. 579, pp. 1005-1039, 2014.

[11] D. Gao, N. Wang, and Z. He, "The bullwhip effect in an online retail supply chain: a perspective of price-sensitive demand based on the price discount in e-commerce," IEEE Transactions on Engineering Management, vol. 64, no. 2, pp. 134148, 2017.

[12] A. Paciorek, "Supply constraints and housing market dynamics," Journal of Urban Economics, vol. 77, no. 1, pp. 11-26, 2013.

[13] J. Brandts, S. S. Reynolds, and A. Schram, "Pivotal suppliers and market power in experimental supply function competition," Economic Journal, vol. 124, no. 579, pp. 887-916, 2014.

[14] I. Kim and A. Petrin, "Tests for price endogeneity in differentiated product models," Journal of Econometric Methods, vol. 4, no. 1, pp. 47-69, 2015.

[15] S. Rezapour, J. K. Allen, and F. Mistree, "Uncertainty propagation in a supply chain or supply network," Transportation Research Part E Logistics \& Transportation Review, vol. 73, pp. 185-206, 2015.

[16] T. Berry and A. Haile, "Identification in differentiated products markets using market level data," Econometrica, vol. 82, no. 5, pp. 1749-1797, 2014.

[17] J. Venables, "Depletion and development: natural resource supply with endogenous field opening," Journal of the Association of Environmental \& Resource Economists, vol. 1, no. 3, pp. 313-336, 2014.

[18] W. Chung, S. Talluri, and R. Narasimhan, "Optimal pricing and inventory strategies with multiple price markdowns over time," European Journal of Operational Research, vol. 243, no. 1, pp. 130-141, 2015.

[19] E. Adida and G. Perakis, "The effect of supplier capacity on the supply chain profit," Annals of Operations Research, vol. 223, no. 1, pp. 1-52, 2014.
[20] Y. Fan, "Ownership consolidation and product characteristics: a study of the US daily newspaper market," American Economic Review, vol. 103, no. 5, pp. 1598-1628, 2013.

[21] H. Liang, J. Zou, K. Zuo, and M. J. Khan, “An improved genetic algorithm optimization fuzzy controller applied to the wellhead back pressure control system," Mechanical Systems and Signal Processing, vol. 142, article 106708, 2020.

[22] H. Zheng, W. Guo, and N. Xiong, "A kernel-based compressive sensing approach for mobile data gathering in wireless sensor network systems," IEEE Transactions on Systems, Man, and Cybernetics: Systems, vol. 48, no. 12, pp. 23152327, 2017.

[23] Z. Huang, X. Xu, J. Ni, H. Zhu, and C. Wang, "Multimodal representation learning for recommendation in Internet of Things," IEEE Internet of Things Journal, vol. 6, no. 6, pp. 10675-10685, 2019.

[24] H. Liang, J. Zou, Z. Li, M. J. Khan, and Y. Lu, "Dynamic evaluation of drilling leakage risk based on fuzzy theory and PSO-SVR algorithm," Future Generation Computer Systems, vol. 95, pp. 454-466, 2019.

[25] Z. Liu, B. Hu, B. Huang, L. Lang, H. Guo, and Y. Zhao, "Decision optimization of low-carbon dual-channel supply chain of auto parts based on smart city architecture," Complexity, vol. 2020, Article ID 2145951, 14 pages, 2020.

[26] Y. Zhang, R. Zhu, Z. Chen, J. Gao, and D. Xia, "Evaluating and selecting features via information theoretic lower bounds of feature inner correlations for high-dimensional data," European Journal of Operational Research, vol. 11, 2020.

[27] H. Liang, A. Xian, M. Min Mao, P. Ni, and H. Wu, “A research on remote fracturing monitoring and decision-making method supporting smart city," Sustainable Cities and Society, vol. 62, article 102414, 2020.

[28] Y. Zhou, D. Zhang, and N. Xiong, "Post-cloud computing paradigms: a survey and comparison," Tsinghua Science and Technology, vol. 22, no. 6, pp. 714-732, 2017. 